\title{
SISIMIQUE: ORÍGENES INDÍGENAS DE UN PERSONAJE DEL CUENTO POPULAR COSTARRICENSE
}

\author{
Adolfo Constenla Umaña
}

\begin{abstract}
This was the incorporation speech of professor Constenla to the Costa Rican Academy of the Spanish Language. It deals with the etymology of the word Sisimique and the origin of the character from Costa Rican folk narrative which bears this name. It concludes that the etymon is the nahuat /tsitsimit/, and that it entered Costa Rican oral tradition by difusion from northern Central America.
\end{abstract}

Señor don Arturo Agüero, Presidente de la Academia Costarricense de la Lengua, Señoras y señores Miembros de la Academia Costarricense de la Lengua, Señoras y señores:

Hace un año que tuve el honor de ser escogido para colaborar, en pro de nuestra lengua y nuestra cultura, con el tan distinguido grupo de intelectuales que integran la Academia Costarricense de la Lengua, que incluye a algunos de mis mejores y más admirados maestros. Mi candidatura tuvo su origen en la generosidad de los compañeros de la Escuela de Filología, Lingüística, y Literatura, quienes propusieron mi nombre. Por ello, me resulta especialmente satisfactorio el que esta ceremonia se esté llevando a cabo en mi querida Facultad de Letras y así tener la oportunidad de manifestarles, una vez más, mi gratitud a todos.

La silla que me ha correspondido es la G, ocupada previamente por don José Basileo Acuña Zeledón, personalidad ilustre que don Alberto Cañas (s.f.: 33-6) caracterizó una vez como "hombre de mucha ciencia y mucho pensamiento" que al mismo tiempo era "maestro por vocación, y además poeta auténtico y culto".

En efecto, don José Basileo destacó por la vastedad de su cultura no sólo dentro de su especialidad, la psicología, sino también en campos como la literatura, la estética, la filosofía y la historia, en los que no se limitó a la erudición sino que realizó aportes tan importantes como sus traducciones de literatura inglesa (véase, por ejemplo, Montejo de Orlich y Acuña 1978) y el extenso libro La Iglesia Católica Liberal. Su historia, sus principios y sus fines. Pero no le bastó la posesión y producción del conocimiento, sino que sintió una necesidad imperiosa de 
difundirlo, lo cual lo llevó a trabajar toda su vida, sin tener necesidad de hacerlo, como eximio profesor tanto de enseñanza secundaria como universitaria.

Como creador, don Abelardo Bonilla, su predecesor en esta Academia y maestro inolvidable de algunos de los aquí presentes, lo consideró (1957: 266) el más profundo de los que llamó "poetas profesores".

Su obra poética testimonia la amplitud de sus inquietudes intelectuales: desde la concepción estética que priva en Proyecciones, pasando por la preocupación religiosa y la reflexión sobre los grandes problemas metafísicos, particularmente patente en Quetzalcoatl, hasta la búsqueda de la identidad americana tanto en los orígenes como en las circunstancias presentes y las espectativas con respecto al futuro presentes en Rapsodia de América. Precisamente, gracias a esta amplitud, tuve el privilegio de conocerlo personalmente: hace unos diez años, enterado de mis trabajos sobre las lenguas y las literaturas indígenas costarricenses, me invitó a dar en su casa unas charlas sobre el tema a un grupo de sus amigos con los que se reunía periódicamente.

En recuerdo de esta circunstancia y del estímulo que recibí de don Basileo para que continuara con esta línea de investigaciones, he decidido que este discurso sea un pequeño aporte en tal sentido, que quiero dedicar a su memoria.

Sin embargo, antes de ocuparme del tema concreto que me propongo tratar, me ha parecido conveniente hacer algunas consideraciones de orden general sobre la pertinencia del conocimiento de las lenguas y literaturas indígenas en el contexto de la Academia Costarricense de la lengua.

Cuando se me comunicó que había sido elegido miembro de ella, distinción que sinceramente puedo decir que no esperaba, me asaltó la duda de cuál sería el motivo de la misma, teniendo en cuenta que han sido las lenguas indígenas, mucho más que la castellana, el objeto de mis investigaciones. Una consulta con los estatutos resolvió esta inquietud; en ellos se señala como segunda finalidad de la corporación: "Promover el estudio y conocimiento de las lenguas indígenas de esta región de América, con especialidad en cuanto puedan haber influido en las alteraciones del habla castellana en Costa Rica y en el enriquecimiento de su vocabulario".

El que la promoción de la investigación de las lenguas indígenas se haya incluido como uno de los objetivos fundamentales de esta Academia habla muy bien de sus fundadores, entre los que, no en vano, se encontraba el padre de la lingüística costarricense, don Carlos Gagini.

El estudio de las lenguas de indígenas de nuestra región es valioso por varios motivos. Contribuye, como el de todas las lenguas del mundo, a nuestro conocimiento de la naturaleza del lenguaje y, en consecuencia, de la naturaleza humana en general; da base al desarrollo de programas por medio de los cuales las distintas etnias aborígenes puedan mantener y robustecer sus respectivas identidades; nos da acceso a las culturas que se expresan por su medio, lo cual incluye una inmensa riqueza de tradiciones orales, $y$, finalmente, a nosotros los costarricenses que tenemos el castellano como lengua materna, nos ayuda en la tarea de definir nuestra identidad, al permitirnos identificar con precisión el aporte de las lenguas y culturas indígenas a nuestra variedad particular del castellano y de la cultura hispánica.

Los numerosísimos nombres de lugar de origen huetar como Aquiares, Arribará, Birrís, Coris, Corrogres, Cuascuá, Cucubres, Chires, Chirobres, Chures, Escazú, Guararí, Irrires, Itiquís, Jaris, Orobres, Paires, Parruás, Patarrá, Picagres, Pigres, Pirrís, Pócares, Porrosatí, Puruces, Purisil, Quercuá, Quitirricí, Siquiares, Siquirres, Surubres, Tacares, Tapantí, Taras, Tarbaca, 
Tatiscú, Ticufres, Tiquires, Tocorí, Toyogres, Tubures, Túfares, Tuis, Turrós, Turrubares, Turrúcares, Tusubres, Urases, Urasca, Uriche y Yacuares, para mencionar algunos, son componente importantísimo del sabor propio de nuestra toponimia.

Términos, también de origen huetar, como arragre, purruja, poró, yurro, cusinga, cosorró, urrú, oropopo, soterré, yigüirro, cubá, curraré, tiquí son parte de lo que caracteriza nuestra habla frente a los otros pueblos hispánicos. Otros como agüizote, apazote, coyol, cegua, cuita, cele, chan, chapulín, chagüite, chile, huizcoyol, chilate, pinolillo, petate, de origen nahua, indican nuestra pertenencia a una región del mundo hispánico integrada por México y Centroamérica; de hecho, en general, fueron traídos por conquistadores y colonizadores procedentes del norte.

Entre estos últimos elementos se incluye el nombre del personaje de la literatura oral hispanocostarricense cuyo origen indígena me dedicaré a aclarar a continuación.

En su libro El abuelo cuentacuentos, otro miembro de esta Academia de gratísima memoria, don Carlos Luis Sáenz, incluye su versión de un cuento, del ciclo de Tío Conejo, llamado "Sisimiqui", escuchado por él en el Monte de la Cruz de San Rafael de Heredia. Este término designa a un tipo de gigante, secuestrador de mujeres. En el transcurso de mis investigaciones sobre arte verbal, el cuento en cuestión me ha sido narrado dos veces: una por don Mario Loaiza, originario de Juan Viñas, provincia de Cartago (véase Constenla Umaña 1985: 48-52) y otra por doña Benigna Ruiz, de la ciudad de Heredia. En el primer caso, el narrador no usó ningún término especial para designar al gigante; en el segundo, se empleó "sisimique". San Rafael de Heredia pertenece al área abarcada por una isoglosa consistente en la presencia de [i] en lugar de la [e] átona final de palabra, de ahí la pronunciación recogida por don Carlos Luis.

Según la versión del narrador juanviñense, que es la más completa de las tres, el gigante se apodera de la esposa de un hombre que, amedrentado por su gran tamaño, no se atreve a enfrentársele. El hombre se encuentra en el bosque con el tigre, que se ofrece a ayudarle a recuperar su esposa y va a luchar con el gigante por el cual es derrotado. Lo mismo ocurre, sucesivamente, con el león y el toro. Cuando el hombre creía su causa totalmente perdida, aparece Tío Conejo y le ofrece igualmente su ayuda. Sin hacer caso de la desconfianza y las burlas del hombre, el conejo, por medio de trucos, vence y mata al gigante.

En las literaturas indígenas de Mesoamérica y de la Sudamérica atlántica es frecuente la existencia de ciclos relativos a ogros tanto masculinos como femeninos. Se trata de seres antropomorfos velludos, muchas veces aficionados a la carne humana, que en algunos casos presentan particularidades como tener los atributos de su sexo exagerados (penes o tetas excepcionalmente largos) o la capacidad de volver los pies hacia atrás y dejar un rastro que engaña por lo que respecta a la dirección. Entre ellos, los más conocidos son, probablemente, los del Area Amazónica, como el curupira (Reichel Dolmatoff 1971: 86) o la ceiuci (Alexander 1964: 303). En el caso de los pueblos chibchas, entre los cuales se cuentan todas las etnias indígenas actuales de nuestro país, son de este tipo los yohó de los ramas (Conzemius 1929: 326), los muérra de los guatusos, los ushidó de los dorasques (Miranda de Cabal 1974: 23-4), las túlu de los bocotaes (Margery Peña 1989) y los nia de los cunas (Holmer 1951:123-7). Los itso' de los bribris y $m \underline{k} k o ̈$ de los cabécares pertenecen a esta categoría también, pero ofrecen la particularidad de poder transformarse en jóvenes atractivas para seducir a hombres a los cuales chupan la sangre y la carne cuando se duermen a su lado por la noche (véase Margery Peña 1986: 52-3). 
De acuerdo con lo que he podido observar, entre las literaturas indígenas costarricenses, es la guatusa la que presenta el tema del ogro libidinoso secuestrador de mujeres, como se puede apreciar en la siguiente traducción de un texto que recogí al excelente narrador don Eustaquio Castro:

Esto es lo que se narra sobre el ogro.

Se dice, pues, se dice que el ogro la vio, se dice que, en efecto, había una mujer en la casa de un hombre. Se dice que era bellísima la mujer.

Y se la robó, y se la llevó a la selva, y fue a meterse con ella en una oquedad. Se dice que en una cueva. Y estuvo con ella allí, tal hizo el ogro.

Y se dice, pues, se dice que, cuando amanecía, se iba. Y regresaba el ogro, y regresaba por la noche $y$, pues, se dice, se dice que se dedicaba a ello toda la noche, a estar gozándola. Se dice, pues, se dice, se dice que dijo la mujer:

-No podía con él, era enorme su pene, en verdad siempre de noche se pasaba haciéndome el amor.

Y se dice que tuvo un hijo con él.

Pues se dice que, según contó ella, el ogro, era muy grande, por todas partes tenía pelo, en todo todo el cuerpo tenía pelo. Se dice que esto contó la mujer.

$\mathrm{Y}$ se dice, pues, se dice que no podía huir porque dejaba cerrado con una piedra.

Se dice, pues, se dice, que tuvo un hijo con él.

Y sucedió que vino el colibrí y le dijo:

-Yo te sacaré de aquí y te irás adonde tu marido. Ciertamente no debes vivir con el ogro, pero le dejarás tu hijo aquí mismo.

Y tuvo un hijo. Sucedió que la liberó el colibrí, el colibrí movió la piedra, y ella pudo huir. Y llegó a decirle a su marido:

-Quiero vivir de nuevo contigo, porque ya escapé y no soy culpable. Yo no quise dejarte, me obligó el ogro.

Y sucedió que le dijo:

-Está bien, viviré de nuevo contigo.

Y dijo el hombre:

-En efecto, iré a matarlo para vengarte.

Y le dijo:

-No harás eso, es enorme, ¿cómo podrías con él? Es imposible que lo mates.

Y el dijo:

-Bueno, está bien.

Esto es lo que se cuenta del ogro que le robó la esposa a un hombre.

Las narraciones sobre los ogros (muérra maráma) constituyen uno de los ciclos de la literatura tradicional guatusa y, en otros textos, se dan otros detalles sobre ellos que completan la imagen del típico ogro indígena: tienen dos codos en cada brazo, sus pies apuntan en la dirección inversa a la cara y les gusta la carne humana. 
¿Es el sisimique uno de estos ogros indígenas incorporado a la tradición cuentística de la etnia hispánica de Costa Rica?

En los otros países que junto con Costa Rica integraron la Federación Centroamericana se presentan términos relacionados. En Nicaragua se trata de sisimico, definido escuetamente por Mántica como "animal mitológico nicaragüense" y en El Salvador, de sisimite, caracterizado por Arauz (1960:145) como "espíritu maligno que persigue y asusta a los niños, siendo a la vez más perverso que el duende". En Honduras, el nombre es también sisimite y se lo concibe (Chapman 1985:215) como un ser velludo que camina con los pies hacia atrás y roba mujeres que lleva a su cueva, además, (Aguilar Paz 1989: 69) es "gigante y antropófago" y toma a los niños cuando están dormidos en sus hamacas y se los come. En Guatemala, finalmente, se denomina sesimite y es un gigante que, según la tradición de los indios chortíes, vive en una cueva de la que surge un río y que tiene los pies vueltos hacia atrás (Fought 1972: 71-74). Hay un cuento hondureño (Chapman ibídem) que coincide mucho, al inicio, con el texto guatuso anteriormente citado: el sisimite (mencionado también como "el oso") secuestra a una mujer y se la lleva a su cueva de donde no la deja salir; la mujer queda embarazada y le nace un niño que presenta características humanas y de sisimite, al mismo tiempo. El resto de la narración trata de las aventuras del hijo del sisimite cuando, tras matar a su padre, se va a vivir entre los hombres.

Por lo que respecta a la palabra sisimiteÚsesimite ÚsisimiqueÚsisimico, la etimología es sin duda nahua, como acertadamente propuso Mántica (ibídem) para la variante empleada en Nicaragua. En pipil de El Salvador, Lyle Campbell recoge el término/tsitsimit/, que glosa del siguiente modo: 'el demonio, el sisimite, el sombrerón (ser sobrenatural)' y que está relacionado con el azteca tzitzimitl (plural tzitzimime) tipo de ser sobrenatural respecto del cual los informantes de fray Bernardino de Sahagún en el siglo XVI hicieron las siguientes menciones:

... los demonios del aire llamados tzitzimites, los cuales han de venir a destruir la tierra con todos los que en ella habitan...

... porque decían y tenían esta fábula o creencia entre sí, que si no se pudiese sacar lumbre que habría fin el linaje humano, y que aquella noche y aquellas tinieblas serían perpetuas, y que el sol no tornaría a nacer o salir; y que de arriba vendrían y descenderían los tzitzimime, que eran unas figuras feísimas y terribles, que comerían a los hombres y mujeres.

El sombrerón es un personaje que, en la tradición oral guatemalteca (Gloria A. de Gutiérrez no lo menciona en su obra de 1993 sobre folclore salvadoreño), se presenta en la forma de "un hombrecito con un sombrero gigantesco" (Uribe 1992:14).

El que se use la misma designación para un gigante y un duendecillo no debe sorprender, pues se sabe que en el pensamiento mítico los contrarios con frecuencia se hacen equivaler: en la tradición salvadoreña sobre los duendes se dice que de cerca se ven chiquitos, pero que de lejos se ven como grandes hombrazos (de Gutiérrez ibídem: 78). De hecho, Chapman (1985: 215) afirma que en Santa Elena, Honduras, le contaron sobre los sisimites que "había montones en las cuevas, que eran chiquitos, panzones, los pies al revés y muy feos, pero que no hacían da- 
ño". La asociación con el aire que se daba en el caso de los aztecas, también se ha documentado en Honduras: Aguilar Paz (1989: 69), narra que en una ocasión, habiendo tapado la gente la salida de su cueva, un sisimite haciendo un gran hueco rompió la tierra por encima y "de un salto, se elevó por los aires, hasta perderse a lo lejos..."

Por lo que respecta a la clasificación en nahuatismos y nahuatlismos, aunque no podamos tener una absoluta seguridad, lo más probable es que sisimite Úsesimite Úsisimique Úsisimico sea del primer tipo, ya que la mayor parte de las hablas nahuas de Centroamérica, que se encontraban concentradas principalmente en la costa pacífica de Guatemala, las regiones occidentales de El Salvador y Honduras y la vertiente pacífica de Nicaragua, no presentan el fone$\mathrm{ma} / \mathrm{t} \neg /$, ortográficamente $t l$. En tal caso, el origen del término habría sido una forma idéntica a la que presenta todavía el pipil salvadoreño, antes citada. La adaptación encontrada en El Salvador y Honduras, sisimite, es la que, de no intervenir ningún fenómeno especial, se esperaría: la - $t$ final de los nahuatismos (al igual que la $-t l$ de los nahuatlismos) se convierte regularmente en secuencia -te en castellano (como ha ocurrido en jocote, tomate, metate, petate, elote, etc.) y el acento se traslada de la penúltima sílaba de la palabra original a la vocal que precede dicha secuencia. La forma guatemalteca sesimite es el resultado de una disimilación de la primera /i/ de /tsitsimit/, de acuerdo con la tendencia de muchas hablas rurales que produce formas como melitar, deligente, menistro. El reemplazo de $/ \mathrm{t} / \mathrm{por} / \mathrm{k} /$ en la variante costarricense sisimique es más difícil de explicar. Es cierto que se dan alternancias entre $/ \mathrm{t} / \mathrm{y} / \mathrm{k} /$ en vocablos atribuibles al sustrato huetar, como en los topónimos TarbacaÚCarbaca, TuralesÚCurales y el fitónimo tirráÚquirrá (Quesada Pacheco 1990: 21), pero sisimique no tiene tal procedencia y lo más probable es que haya sido traído a Costa Rica con posterioridad a la conquista, en vista de que, si bien hubo asentamientos nahuas en este país, fueron pequeños (Fernández Guardia 1975: 24) y su pronta desaparición hace casi imposible que quedaran elementos procedentes de ellos en nuestro castellano.Cabe pensar en una disimilación de punto articulatorio de /t/ provocada por la /s/ precedente, perteneciente como ella a la serie dentoalveolar. La forma documentada en Nicaragua por Mántica sisimico, de todos modos, pareciera tener su mejor explicación en la modificación de un sisimique previo por contaminación con mico, lo cual parece muy razonable en vista de que el personaje es de figura simiesca.

En conclusión, el personaje de nuestra tradición oral de que hemos venido hablando, si bien se encuentra como elemento autóctono de alguna de las culturas indígenas nacionales, en el caso de la etnia hispanoamericana costarricense es un rasgo adquirido, seguramente por difusión, desde el resto de Centroamérica, donde la cultura hispanoamericana lo habría tomado en préstamo a la cultura de los pueblos hablantes de lenguas nahuas. He ahí el origen de este elemento de origen indígena de nuestro castellano y de su literatura oral.

Señoras y señores miembros de la Academia Costarricense de la Lengua: las lenguas y las literaturas populares de nuestro país, en particular las indígenas, han constituido desde muy temprano en mi vida el principal interés, la pasión más constante y la mayor fuente de placer intelectual. Confío en que esto me ayude en el esfuerzo por cumplir los fines de la institución a la que me ha integrado una decisión de ustedes que tanto me honra y por la que les estaré siempre agradecido.

He dicho. 


\section{Bibliografía}

Academia Costarricense de la Lengua. 1925. Estatutos y reglamento. Imprenta Trejos.

Acuña Zeledón, José Basileo. 1927. La Iglesia Católica Liberal. Su historia, sus principios y sus fines. San José: Imprenta Alsina.

1947. Quetzalcoatl. San José: Imprenta Trejos.

1953. Proyecciones. San José: Imprenta Trejos.

1962. Rapsodia de América. Editorial Costa Rica. San José.

s.f. "Discurso de Incorporación a la Academia Costarricense de la Lengua, correspondiente de la española, y respuesta del académico Alberto F. Cañas.” Folleto mimeografiado. Biblioteca de la Universidad de Costa Rica.

Aguilar Paz, Jesús. 1989. Tradiciones y Leyendas de Honduras. Tegucigalpa: Editora Museo del Hombre Hondureño.

Alexander, Hartley Burr. 1964. The Mythology of All Races. Vol. XI. Latin American. Nueva York: Cooper Square Publishers.

Arauz, Próspero. 1960. El Pipil de la Región de los Itzalcos. San Salvador: Departamento Editorial del Ministerio de Cultura.

Bonilla, Abelardo. 1957. Historia y Antología de la Literatura Costarricense. San José: Editorial Universitaria.

Campbell, Lyle. 1985. The Pipil Language of El Salvador. Berlin: Mounton Publishers.

Cañas, Alberto F. s.f. "Discurso del académico Lic. Alberto F. Cañas, en respuesta al discurso de incorporación del profesor José B. Acuña, a la Academia Costarricense de la Lengua." En Acuña Zeledón s.f.

Constenla Umaña, Adolfo. 1985. "Funciones del presente histórico en dos textos narrativos tradicionales costarricenses", Revista de Filología y Lingüística de la Universidad de Costa Rica. 11 (1): 41-62.

Conzemius, Eduard. 1929. "Die Rama Indianer von Nicaragua". Zeitschrift für Ethnologie. 59:291-362. 
Chapman, Anne. 1985. Los Hijos del Copal y la Candela. México D.F.: Universidad Nacional Autónoma de México.

Fernández Guardia, Ricardo. 1975. El descubrimiento y la conquista. San José: Editorial Costa Rica. Fought, John G. 1972. Chorti (Mayan) Texts. Filadelfia: University of Pennsylvania Press, Inc.

Gutiérrez, Gloria A. de. 1993. Tradición oral de El Salvador. San Salvador: Dirección de Publicaciones e Impresos.

Holmer, Nils M. 1951. Cuna Chrestomathy. Etnologiska Studier 19. Gotemburgo, Suecia: Etnografiska Museet.

Mántica, Carlos. 1973. El habla Nicaragüense. San José: Editorial Universitaria Centroamericana.

Margery Peña, Enrique 1986b. "Cuatro leyendas cabécares”. Estudios de Lingüística Chibcha 5:45-57.

1989 ch. "Cuatro relatos mitológicos bocotás de los yé nansére ("seres malos')." Revista de Filología y Lingüística de la Universidad de Costa Rica. 15 (2): 51-73.

Miranda de Cabal, Beatriz. 1974. Un pueblo visto a través de su lenguaje. Ciudad de Panamá: Impresora Panamá. S.A.

Montejo de Orlich, Jessie y José Basileo Acuña. 1978. Poesía inglesa. Antología. San José: Editorial de la Universidad de Costa Rica.

Quesada Pacheco, Miguel A. 1990. “La lengua huetar”. Estudios de Lingüística Chibcha. 9:761.

Reichel-Dolmatoff, Gerardo. 1971. Amazonian Cosmos. Chicago y Londres: The University of Chicago Press.

Sáenz, Carlos Luis. 1994. El abuelo cuentacuentos. San José: Imprenta Nacional.

Sahagún, Bernardino de.1956. Historia General de las cosas de Nueva España. Tomo II. México D.F.: Editorial Porrua, S.A.

Uribe, Verónica. 1992. Cuentos de espantos y aparecidos. Sao Paulo, Brasil: Editora Ática. 